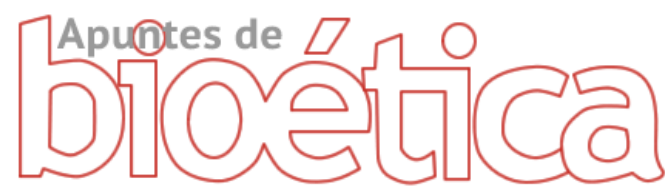

https://doi.org/10.35383/apuntes.v3i1.386

\title{
¿La eutanasia como opción ante el sufrimiento? Una mirada desde la Psiquiatría
}

\author{
Hernández Santilllán G. ${ }^{1}$, Jouve de la Barreda N. ${ }^{2}$
}

\begin{tabular}{ll}
\hline INFORMACIÓN & RESUMEN \\
\hline $\begin{array}{l}\text { Historia del artículo: } \\
\text { Recibido: } 08 \text { de mayo } 2020\end{array}$ & Últimamente, la eutanasia ha encabezado el debate del final de la vida. Se \\
Aceptado: 23 de julio 2020 & plantea el "derecho a una muerte digna"; sin embargo, "morir" no \\
\hline $\begin{array}{l}\text { Palabras claves: } \\
\text { Eutanasia }\end{array}$ & constituye un derecho en sí mismo y la dignidad es un atributo de toda vida \\
Psiquiatría & humana. Por su parte, la Psiquiatría se ha ocupado durante el último siglo \\
cuidados paliativos & de elaborar documentos, como la Declaración de Hawái (1977) y la \\
sufrimiento & Declaración de Madrid (1996) para regular éticamente el ejercicio de la \\
& profesión. Sorprendentemente, países como Holanda y, recientemente, \\
& España aprueban la eutanasia en su legislación, con el riesgo de caer en el \\
& fenómeno "pendiente resbaladiza" y llegar a perder el control. Como \\
& solución, los cuidados paliativos procuran el trato digno de la persona \\
& próxima a morir.
\end{tabular}

\section{Euthanasia as an option facing suffering? A look from Psychiatry}

\section{ABSTRACT}

\section{Keywords:}

Euthanasia

Psychiatry

palliative care

suffering

sense
Euthanasia has been leading the debate about the end of life, lately. The "right to a dignified death" is proposed; however, "dying" does not constitute a right in itself and dignity is an attribute of all human life. For its part, Psychiatry has been concerned during the last century with preparing documents, such as, the Hawaii Declaration (1977) and the Madrid Declaration (1996) to ethically regulate the practice of the profession. Surprisingly, countries like the Netherlands and, recently, Spain approve euthanasia in their legislation, at the risk of falling into the "slippery slope" phenomenon and losing control. As a solution, palliative care seeks the dignified treatment of the person who is about to die.

\footnotetext{
1 Psiquiatra. Doctoranda en Medicina y Cirugía en la Universidad Autónoma de Madrid, Madrid, España. Email: ginahernandez101@gmail.com ORCID: https://orcid.org/0000-0003-0608-9563

${ }^{2}$ Doctor en Ciencias Biológicas por la Universidad Complutense de Madrid, Catedrático Emérito de Genética. Miembro del Comité de Bioética de España. Universidad de Alcalá, Madrid, España. Email: nicolasguah@gmail.com ORCID: https://orcid.org/0000-0003-0348-0268
} 


\section{Introducción}

La vida de cada ser humano está tocada por el dolor, el sufrimiento y la muerte, sin excepción. Estos hechos forman parte de la realidad de cada persona, al igual que el nacimiento, el crecimiento y el envejecimiento, ante los cuales, el hombre no permanece indiferente; sino que, por el contrario, le interpelan a menudo y son motivo de evocación ya sea para la tarea científica como para la producción artística. Precisamente, la forma de reaccionar ante la muerte nos habla de cómo es un pueblo, una cultura y una civilización, y, sobre todo, de cómo es una persona. Actualmente, como consecuencia de los avances de la medicina y la tecnología, es posible retrasar la muerte, tener un aspecto más juvenil, pero no es posible evitarla por mucho que la enmascaremos (Encinas-Guzmán, 2009).

Curiosamente, la idea de que el hombre tiene el "derecho a morir con dignidad" ha dominado el debate bioético contemporáneo relacionado con el final de la vida humana. La mayoría de los que abogan por el derecho a una "muerte digna", entienden que éste incluye el derecho a disponer de la propia vida mediante la eutanasia o el suicidio médicamente asistido, basándose para ello en el respeto a la libertad individual o autonomía del paciente. Así, se afirma que nadie tendría derecho a imponer la obligación de seguir viviendo a una persona que, en razón de un sufrimiento extremo, ya no lo desee (Taboada, 2000). No obstante, la idea del "derecho a la muerte digna" constituye un absurdo, pues, no existe el derecho a algo que ha de suceder de cualquier forma, aunque se encuentre en un horizonte lejano; y la dignidad, por su parte, es inherente a toda persona mientras perdure su vida. Estas dos posturas contrapuestas pueden suponer un motivo de conflicto para el psiquiatra novel o experto que en su actividad clínica intenta aliviar el sufrimiento psíquico de personas que se han visto desbordadas por las dificultades de la vida.
Así tenemos que, la Medicina $y$, en particular, la Psiquiatría, se han interesado por estudiar, comprender, abordar el sufrimiento, tratarlo o, al menos, aliviarlo. Sin embargo, la naturaleza del sufrimiento no ha sido suficientemente estudiada por los psiquiatras. Aún pertenece al campo de los teólogos y los filósofos. El sufrimiento es una compleja mezcla de factores espirituales, emocionales y físicos que trascienden el dolor y otros síntomas de la enfermedad terminal (Kaplan y Sadock, 2008). Ante esta realidad, los médicos están más preparados para el tratamiento de la depresión, pero el sufrimiento, como muestra la evidencia, sobrepasa los conceptos del tradicional modelo biopsicosocial. Se palpa, así, la necesidad de ampliar una perspectiva que abarque enfoques más trascendentales para aproximarse a la existencia humana; algo que además no es nada nuevo, pues también constituye un rasgo característico en la historia del desarrollo y la evolución del hombre.

A lo largo de la historia se ha constatado que el enfoque del final de la vida no ha sido totalmente clarificado aún entre las profesiones sanitarias y ha pasado por varios procesos hasta la actualidad. Así, a partir de los juicios de Núremberg, en la década de 1970, la Asociación Mundial de Psiquiatría tomó nota de que no había textos específicos que establecieran procedimientos éticos en la práctica de la Psiquiatría, en ninguna de sus aplicaciones. De este modo, en 1977, la Declaración de Hawái se convirtió en el primer documento producido por la profesión psiquiátrica sobre cuestiones éticas e incluyó, en relación con la experimentación humana, el requisito específico, por primera vez en la historia, de obtener el consentimiento informado antes de incluir a un paciente en un estudio de investigación, que ya se había aprobado en la Declaración de Helsinki de 1964 para otras áreas de la medicina. En actualizaciones posteriores, se estableció que los psiquiatras, en el contexto de su relación con los enfermos mentales, deben guiarse siempre por el 
respeto de los pacientes, priorizando su bienestar e integridad física (López-Muñoz, 2006).

En octubre de 1987, la World Medical Association hizo pública la siguiente declaración sobre la eutanasia:

La eutanasia, es decir, el acto deliberado de acabar con la vida de un paciente, incluso si se realiza a petición del propio paciente o a petición de sus familiares más allegados, no constituye un proceder ético. Esto no impide que el médico respete los deseos del paciente de que se permita que el proceso de la muerte siga su curso en la fase terminal de la enfermedad. (Kaplan y Sadock, 2008).

Partiendo de esta introducción, los autores de este ensayo se plantean las siguientes preguntas: ¿Qué lugar ocupa la muerte en la existencia humana? ¿Cómo se ha de afrontar el final de la vida? ¿Es lícito para los sanitarios acabar prematuramente con la vida de otro, en aras de mitigar su sufrimiento, como parte del ejercicio de su profesión? Y, por último, ¿qué alternativas éticamente aceptables existen para aliviar el sufrimiento humano al final de la vida?

Este ensayo comprende las siguientes tesis:

1. La muerte y el morir forman parte de la vida.

2. Aun cuando no sea posible cambiar una situación contraria e ineludible, es posible escoger la actitud de afrontarla.

3. La eutanasia ha demostrado ser un fracaso en la práctica médica.

4. Los cuidados paliativos constituyen una herramienta que procura el trato digno del ser humano.

\section{La muerte y el morir forman parte de la vida.}

Los términos muerte y morir requieren una definición: la muerte puede considerarse la suspensión absoluta de las funciones vitales, mientras que el morir es el proceso en el que se pierden esas funciones. El morir también puede verse como una etapa del desarrollo concomitante a la vida, dentro del continuo nacimiento- muerte. La vida puede entrañar muchas mini-muertes: el final de su crecimiento y de su potencial, las enfermedades que afectan a la salud, múltiples pérdidas, el descenso de la vitalidad y el aumento de la dependencia con el envejecimiento y el proceso de morir. El morir y la conciencia que tiene el sujeto de este proceso imbuye a los seres humanos de valores, pasiones, deseos e ímpetus para sacar el máximo partido al tiempo (Kaplan y Sadock, 2008).

Desde una perspectiva más biológica, los animales poseen sistemas cerrados, caducos y mortales. Tienen una vida limitada, condicionada por la organización estructural y funcional de sus células, tejidos y órganos, que una vez desarrollados durante las etapas embrionaria y fetal dependen de los aportes de oxígeno y nutrientes con una limitación temporal por el desgaste y la acumulación de desechos de sus elementos moleculares, intracelulares e intercelulares.

El caso es que, dado que las células no conservan su capacidad de proliferación de forma ilimitada, los tejidos y órganos se desgastan con el tiempo y pierden vitalidad, todo lo cual conduce inevitablemente a la muerte. La Medicina puede solucionar muchos de los problemas puntuales de salud, pero ante un accidente cardiovascular grave, una metástasis que afecta a órganos vitales o un deterioro orgánico debido a causas naturales, llega un momento en que ya no es posible hacer nada y sobreviene la muerte. Los avances médicos han permitido retrasar la muerte en el último siglo, pero la muerte sucede como un hecho inevitable. Los seres humanos, sometidos a los mismos procesos moleculares y genéticos que el resto de los animales, tienen una restricción temporal y una caducidad que raramente sobrepasa los 100 años. 
La persona que está próxima a morir raramente sigue una serie de respuestas regulares que puedan identificarse con claridad y no existe una secuencia fija que pueda aplicarse a todos los pacientes, pero, a pesar de ello, es frecuente encontrar las cinco etapas siguientes propuestas por la psiquiatra, especializada en el tema de la muerte, Elisabeth Kübler-Ross (2008): 1) shock y negación; 2) enfado; 3) negociación; 4) depresión; 5) aceptación. La asistencia de un paciente moribundo es algo muy individual. Los cuidadores y asistentes tienen que afrontar la muerte con honestidad, tolerar amplios márgenes de afecto, conectar con el sufrimiento que padecen los pacientes y sus afligidos seres queridos y resolver los problemas más habituales que vayan surgiendo.

\section{Aun cuando no sea posible cambiar una situación contraria e ineludible, es posible escoger la actitud de afrontarla.}

La muerte es una situación ineludible y, en muchos casos, si no en la mayoría, se acompaña de angustia y dolor. Es una realidad inevitable que todos, sin excepción, hemos de afrontar de un modo u otro. También se puede afirmar que en la vida es posible también experimentar "pequeñas muertes" como es el caso de las pérdidas de personas u objetos significativos, al igual que otro tipo de pérdidas, como las que se presencian en el desarrollo mismo, que comprende el paso de la etapa embrionario-fetal al nacimiento, la niñez a la adolescencia, de la juventud a la adultez y el envejecimiento, propiamente dicho. Así, la vivencia del duelo se convierte también en un rasgo característico dentro de la existencia humana, forma parte de la normalidad; aunque también es verdad, que no todos los duelos se resuelven favorablemente hasta llegar a ser superados, éstos son considerados como "duelos patológicos" y constituyen un motivo de consulta frecuente en Psicología y Psiquiatría.
A propósito de superar el sufrimiento, Viktor Frankl, psiquiatra austriaco que sobrevivió a la experiencia de los campos de concentración durante la segunda guerra mundial, fundó y desarrolló la logoterapia y, en ella, explica el sufrimiento como un cauce para encontrarle un sentido a la vida. De este modo, señala que cuando uno se enfrenta con un destino ineludible, inapelable e irrevocable (p.ej., una enfermedad incurable $o$ un cáncer terminal), entonces, la vida ofrece la oportunidad de realizar el valor supremo, de cumplir el sentido más profundo: aceptar el sufrimiento. El valor no reside en el sufrimiento en sí, sino en la actitud frente al sufrimiento, en nuestra aptitud para soportar ese sufrimiento. Cabe apuntar aquí que no se trata de buscar el sufrimiento por el sufrimiento -esto no denotaría un adecuado equilibrio psíquico-; sino más bien, en adoptar una actitud de aceptación al acoger ese sufrimiento, a la vez de dotarle de un significado. El sufrimiento deja de ser sufrimiento, en cierto modo, en cuanto encuentra un sentido, como suele ser el sacrificio (Frankl, 2004).

Uno de los axiomas básicos de la logoterapia mantiene que la preocupación primordial del hombre no es gozar del placer, o evitar el dolor, sino buscarle un sentido a la vida. $Y$ en esas condiciones el hombre está dispuesto hasta aceptar el sufrimiento, siempre que éste atesore un sentido. No obstante, Frankl (2004) también enfatiza que el sufrimiento no es en absoluto necesario para otorgarle sentido a la vida, ya que, el sentido es posible sin el sufrimiento o a pesar del sufrimiento. Para que el sufrimiento "ofrezca" un sentido a quien lo padece ha de ser inevitable, absolutamente necesario. El sufrimiento evitable debe combatirse con los remedios oportunos; el no hacerlo así sería síntoma de masoquismo, no de heroísmo.

Ahora bien, en el psicoanálisis clásico se sostiene que las dos tareas más importantes de la vida son "amar y trabajar" (Blatt, 2008). En 
esta línea, la psicoterapia tradicional tiende a restaurar en la persona la capacidad para el trabajo y para disfrutar de la vida. Esos objetivos son compartidos también por la logoterapia, aunque avanza un paso más al pretender que el paciente recupere su capacidad de sufrir, si fuera necesario, y por ello encontrarle un sentido al sufrimiento. Sin embargo, asistimos a una sociedad actual que se plantea el bienestar y la calidad de vida como objetivos primordiales. Una sociedad en la que destacan la inmediatez en el disfrute, la escasa tolerancia a la frustración y la poca disposición para la espera de la gratificación. Coincidiendo con la apreciación de una discípula de Frankl en la escuela vienesa de Logoterapia o Análisis Existencial, "este sistema de valores puede ser responsable, ante la realidad de la infelicidad inevitable, del incremento del sentimiento de desdicha por el hecho de no ser plenamente feliz" (WeisskopfJoelson, 1955). A esto se añade, además, la dificultad propia de definir el concepto de felicidad en función de los diversos entornos culturales y generacionales; más aún, cuando se hace con fines de aplicación científica y clínica.

Llegado a este punto, es necesario señalar que la logoterapia intenta que el paciente cobre conciencia plena de sus responsabilidades personales; en consecuencia, le fuerza a elegir por qué, de qué $o$ ante quién se siente responsable. Corresponderá al paciente, por tanto, decidir si debe interpretar su existencia como una responsabilidad ante la sociedad o ante su propia conciencia. Un gran número siente esa responsabilidad ante Dios, a Él deben rendir cuentas; son las personas que no se quedan simplemente en la tarea a cumplir, sino que vuelven la vista hacia quien les ha encomendado esa tarea. En este sentido, Frankl (2004) sostiene además que la logoterapia se encuentra tan lejana del razonamiento lógico como de la exhortación moral. Más aún, la función del logoterapeuta consiste en ampliar y ensanchar el campo visual del paciente hasta que visualice responsablemente el amplio espectro de valor y de sentido contenidos en su horizonte existencial. Enfatiza, además, en que la logoterapia no necesita imponer al paciente ningún juicio de valor, ya que la verdad se impone por sí misma.

Otra figura representativa del siglo XX, más reciente que el anterior y también sobreviviente de la segunda guerra mundial, es Boris Cyrulnik, neurólogo y psiquiatra francés que ha contribuido a difundir a nivel mundial el concepto de resiliencia, esta última entendida como la capacidad de superar la adversidad.

Cyrulnik (2002) señala que, en los campos de concentración, lo que torturaba era lo real: el frío, el hambre, los golpes, la muerte visible, inminente, fútil. Y la ausencia de representación, el vacío de sentido, el absurdo de lo real hacía que la tortura fuese aún más fuerte. Sin embargo, en su emblemático libro "Los patitos feos", también se afirma que hay familias en las que se sufre más que en un campo de exterminio. Esto puede observarse en casos en los que existe algún tipo de desorganización familiar, en culturas en las que se hace callar a las víctimas y se les añade una agresión más, y en las sociedades que abandonan a las criaturas que se considera se han echado a perder, entonces, los que han recibido un trauma conocerán un destino carente de esperanza.

El autor de "Los patitos feos" defiende que hablar de resiliencia en términos de individuo constituye un error fundamental. No se es más o menos resiliente, como si se poseyera un catálogo de cualidades: la inteligencia innata, la resistencia al dolor, o la molécula del humor. Por el contrario, vivir en una cultura en la que se pueda dar sentido a lo que nos ha ocurrido: organizar la propia historia, comprender y dar, son los más simples medios de defensa, los más necesarios y los más eficaces. $Y$ esto quiere decir que una cultura de consumo, incluso en aquellos momentos en que la distracción resulta agradable, no ofrece factores de resiliencia. Alivia durante algunos minutos, como les ocurre a los espectadores ansiosos, que logran olvidarse 
de los tranquilizantes en aquellas noches en que ven la televisión. Sin embargo, para dejar de sentirse malo, para llegar a ser esa persona por cuya intermediación llega la felicidad, es preciso participar en la cultura, comprometerse con ella, convertirse en actor y no seguir siendo mero espectador. Por tanto, la resiliencia no es ni una vacuna contra el sufrimiento, ni un estado adquirido e inmutable, sino un proceso, un camino que es preciso recorrer, y no de forma solitaria, sino, a través de la relación con los demás (Cyrulnik, 2005).

Ahora bien, cabría hacer algunas preguntas de monitoreo social, ¿cómo son los vínculos entre las personas que conforman la sociedad? ¿Cómo se están construyendo esos vínculos y cómo se mantienen? ¿Qué papel juega el sufrimiento como nexo de formación de vínculos en nuestro entorno cultural? No es ajena la experiencia de que el sufrimiento es motivo de unión, y otras veces, de separación. No en vano, Cyrulnik resumió la resiliencia, como capacidad para superar la adversidad, en dos cosas: vínculo y sentido. Podría decirse, entonces, que la resiliencia es la capacidad de superar la adversidad compartiendo un sufrimiento dotado de significado y vivido en comunión con otro $u$ otros. Por ello, no es de extrañarse que, en muchos casos, una persona que se ha planteado la eutanasia como opción al final de su vida o ante un sufrimiento insoportable, desista en adelantar su partida cuando se ve rodeada de afecto y comprensión.

\section{La eutanasia ha demostrado ser un fracaso dentro de la práctica médica}

El debate relacionado al valor de la vida y la aptitud médica ante ésta viene discutiéndose desde tiempos muy lejanos. Al remontarnos a Hipócrates (460 a.C - 370 a.C), se aprecia que ya por entonces, en su famoso Juramento, reclama de los médicos el compromiso de no dar a nadie una droga mortal aun cuando les sea solicitada, ni tampoco dar consejos con tal fin (Taboada,
2000). Con el transcurrir de la historia, el debate ha seguido activo, si bien, se ha visto influenciado por los matices culturales de cada época y lugar.

Así tenemos que, hace poco más de un siglo, después de que salieron a la luz las atrocidades cometidas en nombre del Nacional Socialismo durante la segunda guerra mundial, la imagen de la Psiquiatría en Alemania fue severamente dañada. Sin embargo, recientes publicaciones muestran que Francia, Gran Bretaña y Estados Unidos también formaron parte del discurso inicial sobre la eutanasia a finales del siglo XIX. Unos consideraban la eliminación de pacientes crónicamente enfermos desde un punto de vista eugenésico; otros lo estimaban desde un punto de vista económico. Un tercer punto de vista propuso el derecho a la auto-determinación haciendo hincapié en el derecho del individuo a decidir morir si no valiera la pena vivir. Este último consideraba el asesinato de enfermos crónicos como un acto de misericordia (Noack, 2007).

El primer autor en discutir sobre la eutanasia en Alemania fue el joven estudiante Adolf Jost, quien entonces tenía 21 años. En 1895 publicó su libro "The Right to death", en el cual defendía el suicidio y el suicidio asistido. También preguntó si el estado tenía derecho a matar personas con alguna enfermedad incurable que no podían dar su consentimiento. Todavía más incisiva fue la posterior aportación de Karl Binding y Alfred Hoche, con su trabajo titulado "The Permission to Destroy Life Unworthy of Life". Binding era abogado y Hoche era director de la clínica psiquiátrica de la Universidad de Friburgo. Estos últimos reiteraron el fundamento de Jost, pero lo presentaron de una manera más radical, introduciendo un nuevo lenguaje en el debate, usando términos como por ejemplo "ballast lives" ("vidas de lastre") y "the worthless" (los inútiles) o "lebensunwerte" ("indigno de la vida"). Estas ideas fueron discutidas por muchos médicos durante la década de 1920. La mayoría de los facultativos 
repudiaron estas propuestas. En contraste con las esterilizaciones masivas, la legalización de dar muerte a este tipo de pacientes no fue apoyada por la opinión de la mayoría. Sin embargo, un poco más tarde, durante la guerra se llevaría a cabo el exterminio de pacientes. Al menos 5000 -y, más probablemente 10 000- niños con deformidades congénitas fueron eliminados de esta manera en departamentos especiales para niños (kinderfachabteilungen). El exterminio de adultos enfermos crónicos, la mayoría pacientes psiquiátricos, se ejecutó en dos etapas. La primera fase llamada Aktion T4 se desarrolló entre 1939 y 1941 en Berlín. La segunda fase descentralizada continuó hasta 1945. La cuenta final se situó entre 200000 a 300000 pacientes llevados a muerte (Noack, 2007).

Como en el caso de la eutanasia en niños, los organizadores de Aktion T4 intentaron hacerlo aparecer como parte de la práctica médica, procurando, de esa manera, dar fundamento a sus decisiones para legitimizar sus acciones. Después de dar muerte a las víctimas utilizando gas de monóxido de carbono, los cuerpos inertes fueron quemados. Los familiares recibieron cartas con razones ficticias de muerte. Muchas familias comenzaron a sospechar, pues los rumores del exterminio de pacientes ya habían empezado a correr desde 1940. Cuando emergió la protesta, representantes de la Iglesia Católica jugaron un rol importante en hablar en contra de lo que estaba pasando (Noack, 2007).

Después del fin de la guerra, son conocidos los múltiples encuentros, declaraciones y documentos en materia de Bioética y Jurisdicción que se elaboraron con el fin de proteger y promocionar la vida de cada ser humano, sin importar su condición. Así tenemos que, en 1977, la Declaración de Hawái se convirtió en el primer documento producido por la profesión psiquiátrica sobre cuestiones éticas. Posterior a esta Declaración, que sentó algunas bases éticas para el ejercicio clínico de la psiquiatría y después de varios procedimientos, en 1994, se pidió a todas las sociedades miembros de la Asociación Mundial de Psiquiatría (World
Psychiatry Association, WPA) que proporcionaran todos los códigos de ética que regulaban el trabajo de su profesión. Veintiún países respondieron, de los cuales seis seguían el código médico general, 13 tenían un código especial para psiquiatras, y dos estaban preparando un código de ética para psiquiatras. Además, para obtener una encuesta sobre los derechos de los pacientes con trastornos mentales, se solicitó a todas las sociedades miembros de la WPA que respondieran a una lista de verificación preparada por el Dr. Bertolote de la División de Salud Mental de la Organización Mundial de la Salud (OMS) en Ginebra para la evaluación de las condiciones de derechos humanos de los enfermos mentales (Helmchen, 2000).

Todos esos recursos juntos contribuyeron al producto final de la Declaración de Madrid, que fue redactado varias veces por el Comité de Ética de la WPA, revisado por el Consejo de la WPA, ulteriormente, revisado más de una vez por diversos organismos hasta que se presentó a la Asamblea General de la WPA en Madrid en agosto de 1996 durante el 10 $0^{\circ}$ Congreso Mundial de Psiquiatría, donde fue finalmente avalado. La tercera sección de este documento aborda la necesidad de desarrollar pautas específicas sobre temas especiales que han sido reconocidos por el Comité de Ética de la WPA (Helmchen, 2000).

En la Declaración de Madrid se formularon cinco pautas específicas de este tipo: sobre la eutanasia, la tortura, la pena de muerte, la selección del sexo y el trasplante de órganos. Las posiciones éticas sobre estos temas son complementarias de la Declaración de Madrid. La guía específica sobre la eutanasia se da aquí como ejemplo:

El deber de un médico, ante todo, es la promoción de la salud, la reducción del sufrimiento y la protección de la vida. El psiquiatra, que tiene entre sus pacientes a algunos que están gravemente privados 
de la capacidad y competencia adecuadas para llegar a una decisión informada, debe tener especial cuidado con las acciones que podrían conducir a la muerte sin consentimiento de aquellos que no pueden protegerse a sí mismos debido a su discapacidad. El psiquiatra debe ser consciente de que las opiniones de un paciente pueden estar distorsionadas por enfermedades mentales como la depresión. En tales situaciones, el papel del psiquiatra es tratar la enfermedad. (Helmchen, 2000)

Con todo lo revisado, cabe preguntarse: si la eutanasia no ha dado buenos resultados anteriormente, habiendo sido ya probada en un pasado cercano a la generación actual, permitiendo así un mejor conocimiento de sus efectos y secuelas, además de contar con documentos que la desaprueban, como las Declaraciones que se acaban de exponer, ipor qué sigue abierto el debate de la eutanasia y por qué se insiste en intentar implantarla en las legislaciones que regulan la práctica sanitaria?

Pues bien, después del recuento histórico, pasamos a otro tipo de análisis. Atendiendo a su sentido etimológico, eutanasia quiere decir buena muerte, (eu = bueno, thanatos = muerte) y se refiere a la muerte de una persona causada por otra, en principio, un profesional de la medicina, a veces sin que medie una petición libre y expresa de quien va a morir. En enero de 2002, la Sociedad Española de Cuidados Paliativos (SECPAL), emitió una extensa y clarificadora Declaración en la que definía la eutanasia como la: «Conducta (acción u omisión) intencionalmente dirigida a terminar con la vida de una persona que tiene una enfermedad grave e irreversible, por razones compasivas y en un contexto médico» (Sociedad Española de Cuidados Paliativos [SECPAL], 2002). De acuerdo con esta definición, mediante la eutanasia, una persona pone fin deliberadamente a la vida de otra, considerando que eso le es un bien.
Un caso representativo es Holanda, el primer país en el que se empezó a practicar la eutanasia de forma legal y donde se viene realizando desde hace más de tres décadas. Las etapas más relevantes del camino jurídico que ha seguido hasta la ley actual son los siguientes: En el año 1973 tuvo lugar la primera sentencia prácticamente absolutoria de un caso de eutanasia. En 1984 se la despenalizó. En 1993 se estableció la reglamentación de la eutanasia, y en el año 2000 la liberación de la misma (VegaGutiérrez, 2007).

En el año 1984, la Corte Suprema holandesa sentenció que la eutanasia no sería penalizada si se cumplían cinco condiciones:

1. La petición de la eutanasia debe venir únicamente del paciente y ser enteramente libre y voluntaria;

2. Dicha petición debe ser estable, bien considerada y persistente;

3. El paciente debe experimentar sufrimientos intolerables sin perspectivas de mejora;

4. La eutanasia debe ser el último recurso, y

5. El médico debe consultar con un colega independiente con experiencia en este campo.

Pese a lo estipulado inicialmente, Holanda constituye un ejemplo del fenómeno de la "pendiente resbaladiza" (ver tabla 1). Los tribunales han eliminado varios de los límites considerados como "medidas estrictas de seguridad" introducidas por el Gobierno en 1993. El Gobierno no ha conseguido controlar la práctica, pues la mayoría de los médicos no "notifican" los casos de eutanasia y el Gobierno es incapaz de constatar que se cumplen el resto de las medidas preventivas (Vega-Gutiérrez, 2007).

Por su parte, dos autores holandeses ofrecen un análisis de la evidencia empírica en su país, en el que confirman que «el paso $A$ » (permisividad legal de la eutanasia voluntaria bajo ciertos requisitos) ha dado origen en 
Holanda a un fuerte descenso por la pendiente resbaladiza en la eutanasia. Señalan que el informe de 1990 ha manifestado el fracaso de las «salvaguardas estrictas» establecidas en 1984 por los tribunales y la Real Asociación Médica holandesa, y que no se han cumplido las garantías esenciales ofrecidas por los partidarios de la eutanasia voluntaria. El documento concluye que, aunque ha habido alguna mejora en el cumplimiento de los requisitos de procedimiento, la práctica de la eutanasia voluntaria escapa del control efectivo (Jochemsen y Keown, 1999).

Tabla 1: La pendiente resbaladiza, versión adaptada (Ortega, 2003).

\begin{tabular}{|l|l|}
\hline Nivel & \multicolumn{1}{|c|}{ Descripción } \\
\hline A & $\begin{array}{l}\text { Ley que autoriza la eutanasia o el suicidio } \\
\text { asistido si se dan tres requisitos: } \\
1^{\circ} \text { plena voluntariedad } \\
2^{\circ} \text { condición de enfermo terminal } \\
3^{\circ} \text { padecer dolores insoportables. }\end{array}$ \\
\hline B & $\begin{array}{l}\text { Se permite la eutanasia no voluntaria e } \\
\text { involuntaria (pacientes en coma, recién } \\
\text { nacidos con malformaciones, ancianos } \\
\text { dementes o enfermos con perturbaciones } \\
\text { mentales). }\end{array}$ \\
\hline C & $\begin{array}{l}\text { Se permite la eutanasia o el suicidio } \\
\text { asistido en enfermos incurables no } \\
\text { terminales, o que no están en situación } \\
\text { irreversible, o con enfermedades de las } \\
\text { que se pueden curar. }\end{array}$ \\
\hline D & $\begin{array}{l}\text { Se permite la eutanasia por motivos de } \\
\text { sufrimiento psicológico, por pérdida de } \\
\text { la autonomía, escasa calidad de vida, } \\
\text { sentimiento de ser una carga económica, } \\
\text { etc. }\end{array}$ \\
\hline
\end{tabular}

Datos más recientes señalan que en el año 2019 se constató que los casos de eutanasia bajaron en Holanda por primera vez en una década. 6126 personas eligieron morir así, un 7\% menos que en 2017 (Ferrer, 2019). Por su parte, en España, en el mes de febrero de 2020, el Congreso inició los procedimientos para la tramitación de la propuesta de una ley despenalizadora de la eutanasia y auxilio al suicidio. Este acontecimiento ha generado mayor polémica en torno al tema. Como señala el Comité de Bioética de España en una declaración sobre la tramitación parlamentaria de esta reforma, este procedimiento de iniciativa legislativa que no requiere de informes consultivos, preceptivamente, resta riqueza al necesario debate sobre una norma de un enorme calado social, ético y legal (Comité de Bioética de España [C.B.E], 2020). Quienes discuten una Ley de esta naturaleza remarcan los resultados que se están obteniendo en Holanda, como antecedente, en el que se ha demostrado que es una medida equivocada porque se dan casos en los que no es el paciente quien decide libre y voluntariamente y no se respetan los protocolos establecidos (Cruz, 2020).

\section{Los cuidados paliativos constituyen una herramienta que procura el trato digno del ser humano.}

La doctora Marguerita S. Lederberg, del Memorial Sloan-Kettering Cancer Center de Nueva York, ha hecho la siguiente observación:

Un ser humano en el trance de morir, cuyas necesidades físicas, sociales, emocionales y espirituales son atendidas de forma efectiva, rara vez pedirá ayuda para suicidarse, y los miembros de la familia, si han recibido ayuda y apoyo adecuados, obtienen una profunda sensación de paz por haber ayudado a su ser querido a morir sintiéndose amado y seguro. (Kaplan \& Sadock, 2008)

Se ha señalado en varias ocasiones que la relación médico-paciente es una relación asimétrica, una relación en la que entra en juego el poder. Planteado de esta manera, cobra sentido la denominación de "facultativo" dada a quien se le otorga la "facultad" -valga la redundancia- o el permiso de entrar en la 
intimidad de otra persona, de presenciar su debilidad, y de quien se espera ayuda y servicio, puesto que ha sido considerado más sabio, más prudente, más entendido en materia de sufrimiento humano, ya que ha recibido la preparación necesaria y ha sido reconocido como tal socialmente. Además, con cierta frecuencia, los médicos se ven revestidos de estas expectativas por parte de sus pacientes, quienes les atribuyen, asimismo, consciente 0 inconscientemente, cualidades y valores como la solidaridad, la compasión y el respeto, por mencionar algunos ejemplos.

Ahora bien, aun en consideración de la debida formación exigida por parte de la sociedad para ejercer la Medicina, ¿quién puede convertirse en juez para decidir cuándo la vida de otra persona es digna o no de ser vivida?, ¿quién puede decidir si la vida de otra persona es lo suficientemente plena para luchar por su prolongación con más o menos medios? Ante el sufrimiento $o$ el dolor causado por una enfermedad, cuando éste se puede paliar con la aplicación experta de una sedación farmacológica adecuada, se debe hacer, pues. El valor de la vida es superior a ninguna otra consideración.

Por supuesto, es aceptable pensar en una limitación de los medios terapéuticos desproporcionados. Lo que es más discutible es establecer criterios de prioridad en la atención sanitaria en las personas más jóvenes, o aquellas que bajo criterios arbitrarios y relativos de utilidad social se piense puedan aportar más a la sociedad. Quitar la vida a un enfermo terminal, aunque se pretenda por compasión y a petición de éste, no es un acto médico. El Art. 36 del Código de Ética y Deontología Médica de la Organización Médica Colegial Española (Consejo General de Colegios Oficiales de Médicos, 2011), reformado en 2011 , señala que «El médico tiene el deber de intentar la curación o mejoría del paciente siempre que sea posible. Cuando ya no lo sea, permanece la obligación de aplicar las medidas adecuadas para conseguir su bienestar, aun cuando de ello pudiera derivarse un acortamiento de la vida. El médico nunca provocará intencionadamente la muerte de ningún paciente, ni siquiera en caso de petición expresa por parte de éste».

Ante un pronóstico de muerte inevitable sólo debería haber una postura a adoptar, la de procurar los cuidados paliativos para evitar el sufrimiento, manteniendo al mismo tiempo al paciente en las mejores condiciones físicas, psíquicas y espirituales.

Cuando se considera que ya no se puede hacer nada por salvar la vida de un enfermo, no se trata de aplicar medidas extraordinarias que no beneficiarán al paciente, sino de paliar su sufrimiento y acompañarle hasta el momento final, sin dejar de suministrar los cuidados mínimos.

La Sociedad Española de Cuidados Paliativos (SECPAL) señala que: "Ante un paciente en situación terminal lo que se hace o se deja de hacer con la intención de prestarle el mejor cuidado, permitiendo la llegada de la muerte, no sólo es moralmente aceptable, sino que muchas veces llega a ser obligatorio desde la ética de las profesiones sanitarias» (SECPAL, 2002).

La Organización Médica Colegial Española aprobó en febrero de 2009 una Declaración sobre Ética de la sedación en la agonía (Consejo General de Colegios Oficiales de Médicos, Febrero de 2009), que entre otros puntos señala que: «En la sedación se busca conseguir, con la dosis mínima necesaria de fármacos, un nivel de conciencia en el que el paciente no sufra, ni física, ni emocionalmente, aunque de forma indirecta pudiera acortar la vida. En la eutanasia se busca deliberadamente la muerte inmediata. La diferencia es clara si se observa desde la Ética y la Deontología Médica».

En esta misma línea, casi todos los códigos éticos para la práctica de la Medicina y la 
Psiquiatría subrayan la importancia de la atención a la persona y profesan prioridad para el bienestar del paciente en el encuentro clínico por encima del bienestar del propio terapeuta. La preocupación de lo que es bueno para el trastorno del paciente es una cosa y una preocupación legítima de la Psiquiatría, sin duda. Sin embargo, la pregunta "iqué es lo bueno para la persona (y no simplemente su trastorno, tratamiento, cerebro o mente)?" va más allá del abordaje biopsicosocial del modelo clásico de la Medicina.

Ésta pregunta es la que se plantea la Psiquiatría-centrada-en-la-persona (personcentered psychiatry, PCP): "qué es lo que es bueno para la persona". Apreciar al paciente en todas sus otras capacidades también lo convierte no solo en un receptor, usuario o consumidor de atención médica, sino, en un participante activo que puede contribuir a la comprensión diagnóstica de sus dificultades, su tratamiento y las decisiones tomadas en su atención médica. Al afirmar que el paciente es una persona autónoma, el clínico le concede la facultad de participar en su proceso de curación (Christodoulou, 2016), de mejoría o de recuperación.

De esta forma, la Psiquiatría Centrada en la Persona (PCP) propone que cada ser humano tiene un valor inherente en sí, y este valor sólo puede captarse a través de la compasión o el amor en un acto de apertura a la trascendencia del otro, lo cual excede a la perspectiva actual de cada uno. (Christodoulou, 2016). En este marco de abordaje dentro de la práctica de la Psiquiatría, se consideran las siguientes pautas esenciales en la aplicación clínica de los cuidados paliativos: favorecer la calidad de vida de los pacientes; su bienestar físico y funcional; su bienestar y funcionamiento psicosocial; su bienestar espiritual; su percepción de cuidado; y el bienestar y el funcionamiento de su familia (Grassi L., 2016).

\section{Conclusiones}

- El dolor, el sufrimiento y la muerte son hechos propios en la existencia humana, su llegada es inevitable, no hay opción de elegir si experimentarlos o no, y, por tanto, no es válida la consideración de la muerte como un derecho. Asimismo, la dignidad es un atributo que recibe cada ser humano indistintamente, sin importar su condición, de ningún tipo, ya sea racial, sexual, cultural, nivel de productividad o de otra índole. Cada vida humana es digna de ser vivida $y$, por tanto, no cabe hablar de muerte digna.

- Puesto que muchas veces no es posible eludir el sufrimiento, el ser humano dispone de otros medios para superarlo, uno de ellos, es la aceptación. Haciendo uso de su libertad interior, la persona es capaz de acoger su dolor y dotarlo de sentido, con la posibilidad, inclusive, de utilizarlo como medio para obtener un bien para consigo mismo o para los demás.

- Ahora bien, desde los orígenes de la práctica de la Medicina a lo largo de la historia, como se registra en tiempos de Hipócrates, han sido claramente establecidos la visión del valor de la vida y el rol del médico en su labor por protegerla, promoverla y cultivarla. Sin embargo, pese a los fracasos comprobados de la eutanasia en contextos como el de la segunda guerra mundial o en la actual Holanda, el debate en relación al final de la vida continúa abierto. Es tarea de los profesionales sanitarios replantearse los motivos que los llevaron a elegir su profesión, actualizar sus propósitos y revisar los valores con los que ejercen su práctica clínica. También es un deber estudiar detenidamente y analizar los aspectos relacionados a la ética de la práctica médica en cada contexto sociocultural, para aplicarlos, ulteriormente, a la gestión y administración de servicios de forma 
multidisciplinaria, a fin de que los errores de antaño no se vuelvan a cometer.

- Asimismo, la verdadera calidad de vida en una sociedad no se mide únicamente por las oportunidades de placer, el nivel de productividad o, simplemente, el acceso a recursos en aras del bienestar físico o psicológico. La verdadera calidad de vida en una sociedad se observa, sobre todo, a través de la organización y conexión entre sus miembros, esto es, de los vínculos que existen entre ellos, de su capacidad de compartir su experiencia vital con reciprocidad y -por qué no decirlo- con dadivosidad. Aquí también toma partido el compartir del sufrimiento y la capacidad y posibilidad de acompañarse mutuamente en el duro trance de la muerte. En este sentido, los cuidados paliativos brindan a la persona que va a morir, la asistencia necesaria para mitigar su dolor, a la vez que le proporciona las medidas apropiadas para no sentirse solo - sola, procurando la cercanía y la participación de aquellos quienes le son más cercanos.

- En el campo de la Psiquiatría, la eutanasia puede suponer un importante conflicto para quien lo practica, ya que, ante un paciente con ideas autolíticas o conductas parasuicidas, la actitud terapéutica habitual es procurar preservar la vida. La atención médica consiste en valorar el sufrimiento psíquico de la persona que consulta, a fin de indagar las causas o condiciones que le llevaron hasta ese punto. En gran parte de los casos, subyace un episodio depresivo; en otros, la ideación o conducta autolítica forma parte de otros tipos de trastornos mentales, más o menos graves, que también pueden ser tratados. En cualquier caso, la actitud terapéutica es extremar la vigilancia para evitar que el paciente se haga daño a sí mismo o hacia los demás. En este contexto, el principio de autonomía no se da por vulnerado, pues se entiende que -y muchas veces es corroborado por el propio paciente, la persona ha llegado hasta ese punto, no porque "no quiera seguir viviendo", sino, porque "no quiere seguir viviendo asI", y que, en ese momento no es capaz de decidir por sí mismo. Este "asi" constituye la vivencia crítica y desbordante que empuja a la persona a escapar de su realidad vital, a costa de sí misma. Es esta vivencia la que hay que "mejorar" a través de la terapia (farmacológica, psicoterapéutica, etc.), con el objetivo de que la persona sufriente pueda encontrar o dotar algún sentido a su dolor, sirviéndose, además, del vínculo con otra persona, terapeuta o no, cercana o no a su entorno.

- En la línea de la logoterapia, una pregunta clave podría ser la que Frankl hacía a sus pacientes: "¿Por qué no se suicida usted?": mientras que, para quien ha sobrevivido a un intento autolítico, la pregunta podría formularse: "¿Por qué no se había suicidado usted hasta entonces o hasta ahora?". Continuando con el corolario "quien encuentra un porqué, encontrará un cómo" (Frankl, 2004). De modo que, el rol del terapeuta, psiquiatra, psicólogo u otro profesional, consiste sobre todo en acompañar al paciente en su búsqueda de sentido mientras sufre, $y$, cuanto menos, aplacar su soledad, empleando para ello los medios necesarios.

- Afortunadamente, durante las últimas décadas hemos asistido a la denominada "reforma psiquiátrica", la cual, aun con sus simpatizantes y detractores, no deja de ser un importante hito en la Psiquiatría y un cambio de paradigma para quienes trabajan en Salud Mental y se dedican al cuidado de los demás. Las personas que padecen trastornos mentales, o dolencias psíquicas de cualquier grado, no tienen vidas menos dignas de ser vividas porque no produzcan lo que los demás o por el gasto que su cuidado implique; por el contrario, a raíz de 
esta Reforma, se ha observado que es posible integrarlas en la sociedad, que pueden desempeñarse en cargos de trabajo y de responsabilidad, según su capacidad y con una adecuada supervisión. Asimismo, estas vidas a menudo son muy significativas para otras vidas, es decir, hay un valor inmaterial en su existencia que llega hasta la trascendencia.

- Actualmente, se está procurando brindar una atención más personalizada hacia quienes consultan en Salud Mental, partiendo de una mirada más amplia que ponga el foco no sólo en lo patológico, sino, sobre todo en lo sano, en lo que se puede rescatar y potenciar. Es tarea de los profesionales de Salud Mental y de la sociedad entera integrar en ella a todos sus miembros, en la medida de lo posible. La vida de una persona es digna en sí misma, es complejo valorarla y está proscrito el juzgarla con nuestros frágiles sentidos y limitada razón, al menos, desde la Medicina. Ante una persona que sufre y que pide ayuda abriéndonos su mundo interior, cabe, cuanto menos, respeto y compasión.

\section{Bibliografía}

Blatt, S. (2008). Una polaridad fundamental en psicoanálisis: implicaciones para el desarrollo de la personalidad, la psicopatología y el proceso terapéutico. Aperturas Psicoanalíticas.

Christodoulou G., V. S. (2016). Ethics in PersonCentered Psychiatry. En B. M. Mezzich J., Person Centered Psychiatry (págs. 35-46). Suiza: Springer.

Comité de Bioética de España (C.B.E.). (Madrid, 4 de marzo de 2020). Declaración del Comité de Bioética de España sobre la tramitación parlamentaria de la reforma legal de la eutanasia y auxilio al suicidio asistido. España.
Comité Directivo de la SECPAL. (26 de enero de 2002). Declaración sobre la Eutanasia de la Sociedad Española de Cuidados Paliativos. Barcelona.

Consejo General de Colegios Oficiales de Médicos. (Febrero de 2009). Ética de la sedación en la agonía. España.

Consejo General de Colegios Oficiales de Médicos. (Julio de 2011). Código de Deontología Médica. Guía de Ética Médica. . España.

Cruz, M. (12 de Febrero de 2020). El congreso aprueba regular por ley la eutanasia con 201 votos a favor, 140 en contra y dos abstenciones. El Mundo.

Cyrulnik, B. (2002). La creatividad de los descarriados. En B. Cyrulnik, La creatividad de los descarriados (págs. 2730). Barcelona: Gedisa.

Cyrulnik, B. (2005). Conclusión. En B. Cyrulnik, Los patitos feos (págs. 209-216). Barcelona: 2001.

Ferrer, I. (2019). Las eutanasias bajan en Holanda por primera vez en una década. El País.

Frankl, V. (2004). El hombre en busca de sentido. Barcelona: Herder.

Frankl, V. (2004). El sentido del sufrimiento. En V. Frankl, El hombre en busca de sentido (págs. 134-137). Barcelona: Herder.

Frankl, V. (2004). La esencia de la existencia. En V. Frankl, El hombre en busca de sentido (págs. 131-133). Barcelona : 2004.

Grassi L., R. M. (2016). Person-Centered Paliative Care. En B. M. Mezzich J., Person Centered Psychiatry (págs. 487-500). Suiza: Springer.

Helmchen H., O. A. (2000). From the Hawaii Declaration to the Declaration of Madrid. Acta Psychiatrica Scandinavica, 20-23.

Jochemsen \& Keown. (1999). Voluntary euthanasia under control? Further 
empirical evidence from the Netherlands. Journal of Medical Ethics, 16-21.

Kaplan \& Sadock. (2008). Asistencia al paciente terminal y medicina paliativa. En K. \&. Sadock, Sinopsis de Psiquiatría (págs. 1359-1370). Barcelona: Wolters Kluwer Health España.

Kaplan \& Sadock. (2008). Desarrollo del ser humano a lo largo del ciclo vital: La muerte, el morir y el luto. En K. \&. Sadock, Sinopsis de Psiquiatría (págs. 6169). Barcelona: Wolters Kluwer Health España.

Kaplan \& Sadock. (2008). Eutanasia y suicidio asistido por el médico. En: Asistencia al paciente terminal y medicina paliativa. En K. y. Sadock, Sinopsis de Psiquiatría (págs. 1368-1370). Barcelona: Wolters Kluwer Health España.
Noack T., F. H. (2007). Eugenics, Euthanasia, and Aftermath. International Journal of Mental Health, 112-124.

Ortega, I. (2003). La pendiente resbaladiza. ¿llusión o realidad? "Annales Theologici", 107-112.

Taboada, P. (2000). El derecho a morir con dignidad. Acta Bioethica. P. Universidad Católica de Chile. , 91-101.

Vega-Gutiérrez J., O. I. (2007). La "Pendiente Resbaladiza" en la Eutanasia en Holanda. Dialnet, 89-104.

Weisskopf-Joelson, E. (1955). Some Comments on a Viennese School of Psychiatry. The Journal of Abnormal and Social Psychology, 701-703. 